\title{
Aboriginal Identity: A Perspective on Hegemony and the Implications for Canadian Citizenship
}

Frank Deer

University of Manitoba

\begin{abstract}
National identity can be a difficult concept to define in Canada, a difficulty that may be particularly prevalent for Canada's Aboriginal people. Identity, whether national or ethnocultural, may be problematic to conceptualize for Aboriginal people because of dominant postcolonial influences that are reflected in everyday life. Identity, an individual's collective understanding of themselves as a unique, separate entity is frequently associated with ethnic and racial affirmations of distinctness. Consequently, Canada's national identity may be fragmented by its various ethnic and racial groups. Canada's Aboriginal people, who have been impacted by a history of European influence through colonization, have consequently struggled with the notion of Canadian identity, a struggle that is prevalent in the field of education. The following will be an exploration of the issues associated with Canadian identity, and how Aboriginal identity relates to that conception of citizenship development for Aboriginal students in Canadian schools. To support this exploration, this article will explore: (a) identity development in a postcolonial and transcultural society, (b) identity negotiation in contemporary Canadian society, and (c) the implications for citizenship development in Canadian education.
\end{abstract}

Keywords: Aboriginal identity; hegemony; postcolonial; transcultural; citizenship 


\section{Aboriginal Identity: A Perspective on Hegemony and the Implications for Canadian Citizenship}

\section{Socio-Cultural Evolution and Canadian Aboriginals}

There are numerous theories regarding socio-cultural evolution in the fields of sociology and anthropology (Trigger, 1998). The central tenet concerning such forms of evolution is the notion that collective beliefs, values, traditions, societal needs, ethnicity, and social relationships are subject to transformation over long periods of time (Ferguson, 2005). Socio-cultural evolution, the process of continuous change and adaptation in a society or culture over time, may not be a passive process in some of its manifestations in modern Western society (Dennis, 1996). Rather, socio-cultural evolution can be the result of the deliberate or unintentional exercise of power and social manoeuvring (Ortner, 2006). The existence of hegemonic relationships-those where individuals of lower social standing are politically, economically, and socially dominated by the ruling class, in ethnically diverse societies_ can be regarded as an essential precursor to such evolution. In citing Marxist ideals of societal progress, Cashmore (1996) stated:

The dominant ideas of any age are the ideas of the ruling class.... What is accepted as common sense, the obviously correct way things are, is not a neutral perception of the world, but a particular way of grasping reality which fits in neatly with the existing social order. In other words, the bourgeoisie's leadership extends from the material world into people’s minds. (pp. 156-157)

Canadian history of the last few centuries suggests that the hegemonic relationships described by Cashmore, have existed and have had a profound impact on the socio-cultural evolution of, amongst others, Canada's Aboriginal peoples (Ray, 2005). It would be remiss to explore Aboriginal history and overlook the changes that many of Canada's Aboriginal peoples have endured from a state that can be characterized as traditional, to a condition of Europeanization, where Aboriginal customs and ways of life have come to resemble their colonizers (Adams, 2000). Elements of such Europeanization can be readily observed in the way many of Canada’s Aboriginal peoples currently live their lives (Findlay, 2000).

Europeanization has influenced the formation of an identity for Aboriginal people that reflects colonization, where aspects of traditional knowledge, heritage, and consciousness can be difficult to discern (Niezen, 2003), especially with mixed-blood and urban Aboriginals (Lawrence, 2004). As ever-present as socio-cultural evolution is for Aboriginal peoples in Canada currently, one may argue that aspects of this sort of evolution are, broadly speaking, unwelcomed by Canada's First Peoples (Alfred, 1999). Perhaps the most concerning phenomenon related to this form of evolution is the role of education; a concern is often articulated by asserting that contemporary education encourages the transmission of ideals, beliefs, and cultural mores to Aboriginal children, thus shrouding pre-existing characteristics of identity. As Schissel and Wotherspoon (2003) wrote, "Cultural practices and belief systems associated with Aboriginal heritage are often ignored or undermined in conventional education" (p. 2). If one considers that schools are sites where children's personalities and virtues are developed (Emberley \& Newell, 1994) and where children are prepared for active citizenship 
(Cogan, 2000), then the importance of education as a tool for children's social development may be appropriately understood (Giroux, 1997).

Education can have an important role in the socio-cultural evolutionary process, with Canadian Aboriginal identities being adversely impacted as a result (Battiste \& Semaganis, 2002). Yet, the development of Aboriginal scholarship in the social sciences, accompanied by evolving political activism amongst Canada's First Peoples, have spawned the emergence of an awareness of the neo-colonial climate in which Aboriginal peoples find themselves (Turner, 2006). Rediscovering and asserting an identity that is congruent with the traditions, values, beliefs, and consciousness of Canada's Aboriginal peoples requires transcendence from the identity that has been placed upon them (Waldram, 1997).

The following will explore the impact of Eurocentric culture upon Aboriginal identity in Canada and how these impacts are prevalent through Eurocentric educational practices. Identity, an individual's collective understanding of themselves as a unique, separate entity, can be regarded as an essential element of citizenship if one considers citizenship as membership in a united community (Manville, 1990). The educational implications of this notion are clear when one considers that Canadian citizenship development is a primary responsibility in virtually all Canadian schools (Li, 2002). These implications were reflected by Levin (1998), who wrote:

[Schools] focus on moral principals [sic] and questions as being primary over technical ones. This means that those in the school, or involved with the school, would always be asking questions such as "is this right?" ”Is this connected with making the world a better place?" "Is this consistent with principles of justice, caring, and equity?” (p. 64)

With Aboriginal education becoming a developing field of study and practice in education, the Aboriginal perspectives that may be associated with Levin's view on moral principles might be worth considering. Virtue, improvement of the human condition, and the tenets that may be associated with a principled education may be beneficial from an appropriate Aboriginal perspective when such education involves Aboriginal peoples.

In writing this article, I recognize and affirm the importance of Canada's multicultural mosaic of numerous, diverse cultural roots and their relevance to national social betterment. Essential to the issues of identity development and maintenance are the relationships between Aboriginals in non-Aboriginals in Canada.

\section{Background: Identity Negotiation in Canada}

Identity may be regarded as an essential element to a national conception of citizenship and one's membership in a given society (Heater, 1999). Identity, the set of personal and social characteristics that allows an individual or collective to assert a measure of distinctiveness (Rohmann, 1999), is frequently characterized along ethnic lines (Johnson, 2006), and is, thus, influenced by ethno-cultural mores (Holder, 2006). Furthermore, an important aspect of identity is the condition of asserting one's self (or one's community) as having some similarities with a self of the past and with a self of the future (Perry, 2002). The establishment of a collective 
national identity in a country like Canada may be made problematic by the numerous ethnic identities existent in the country today. In discussing the issue of "ethnonationalism," the movement espousing all people’s right to be part of a nation, Levin (1993) wrote:

The demand of the state for every people is the strong sense of ethnonationalism. Reconciling the strong version of this ideal with the institutional realities of a state for every person is, however, a practical impossibility. That there are far fewer states than ethnic groups makes the depth of attachment to the ideal and the sense of deprivation in its frustration all the more poignant. The politics of ethnonationalism worldwide draws its importance not from this disproportion of numbers, but from the fact that most states are culturally pluralistic and that more than half the governments of these independent states must deal with political claims made on an ethnic basis where there are few if any workable solutions. (p. 3)

Levin's discussion reflects a dilemma within Canada's population. For all of the different ethnic groups that call Canada home, a shared, national identity may be problematic (Cohen, 2007). Canada's First Peoples have been inundated with tacit and tactile elements of a dominant identity (Johnson, 2006), a state of affairs that has impeded the assertion and celebration of the cultural mores of these peoples. An example of such impediments was reflected by Frideres and Gadacz (2008), who wrote:

The organization of Indians into their present-day bands can be understood as a result of the draconian steps taken against Aboriginal people by government. The government, in a sense, forced Aboriginal persons to deal with them as a band, and, over time, this has become the basis upon which Aboriginal and non-Aboriginal people operate. Over time, Aboriginal people have accepted the band as the focus of their identity. (p. 52)

\section{Aboriginal Struggles with Identity: Past and Present}

Canada is a prosperous, democratic country where opportunity for personal growth and material gain has encouraged foreigners from other countries to migrate here for generations (Ignatieff, 2000; United Nations Development Programme, 2007). Population growth due to immigration, coupled with the development of a capitalist economy where the ideals related to economic and professional excellence, equity, and competitiveness (Emberley \& Newell, 1994) have obscured what Canada's Aboriginal peoples have traditionally valued (Barron, 2002). For many Aboriginals, especially those living in urban settings, many aspects of daily life are lived in a modern Eurocentric context (Lawrence, 2004). Aspects of life that are frequently perceived as benign, such as clothing, technology, and various forms of media, as well as important aspects of self-concept such as one's profession, religion, and place of residence, can be frequently characterized as "mainstream." The consequence from such a life can be confusion regarding what personal and national identity means. This confusion can occur early in life when children are in school (Giroux, 1997), where Aboriginal children can be either subjugated by a dominant culture, or exposed to an education that is not inclusive of their cultural mores. Some writers (Friesen \& Friesen, 2002; Schissel \& Wotherspoon, 2003) have suggested that in the last decade, Canadian education systems have imposed programming that has been far more reflective of the 
dominant colonial power, and thus, have impacted identity development for Aboriginal students. As Battiste \& Semaganis (2002) wrote, "loyalty and allegiance to Eurocentric civilization and oppression were glorified into daily curricula” (p. 93). Such glorification may have significant implications for Aboriginal peoples' identities as well as their relationships with other Canadians.

The relationships between Canadian Aboriginals and their colonizers have been described as a form of social space where these two peoples negotiate the state of their association with one another; a space in which social status is frequently contested (Erasmus \& Sanders, 2002). Little Bear (2000) described this social space where the spiritual, historical and social perspectives of Canadian Aboriginals and non-Aboriginals are dichotomous to a point that reconciliation of the two parties is problematic. Battiste and Semaganis (2002) suggested that the disparity between the dichotomized perspectives has had an adverse effect on the establishment of a concept for a shared identity that both Aboriginals and non-Aboriginals can accept. Ermine (2007) described a relationship between Indigenous and non-Indigenous peoples as a form of ethical space in which focus is brought upon "our personal capacity and our integrity to stand up for our cherished notions of good, responsibility, duty [and] obligation” (p. 195). Common to these characterizations is the notion that the colonial and postcolonial history of Canada may have had a detrimental impact on the already disparate ethnic differences between these two groups of peoples.

Scholars have attempted to illustrate the strained relationships, and subsequent identity struggles, between Aboriginal and non-Aboriginal perspectives, experiences, and history. For example, Battiste (2005) used a Venn diagram to show this relationship and the ethical space that exists between two spheres of perspective, a relationship that she referred to as Jagged World Views Colliding, in reference to the scholarly work of Little Bear (2000). Battiste's discourse was intended to emphasize the socio-cultural space between Aboriginal and non-Aboriginal peoples and how this area can be contentious in regard to how the two groups address each other. Essential to this illustration is the notion that the two groups are quite culturally different. Using a similar approach, Figure 1 illustrates the social space where negotiation of association and status can be characterized as an abstract region where the two cultural perspectives are "united." Making this model different is the emphasis placed on the area of identity negotiation-an area in which the evolutionary process that may be associated with transculturation may be prevalent. 


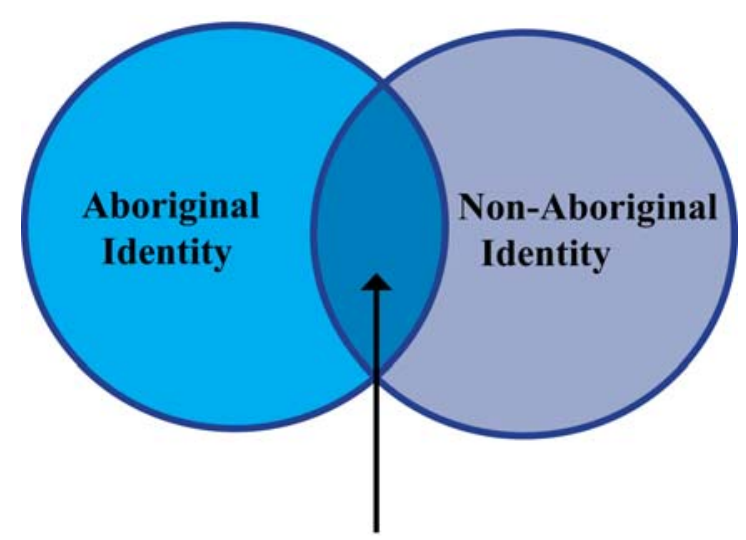

Inter-Ethnic Overlap: An Area of

Identity Negotiation That May be

Subject to Hybridism.

Figure 1. Contrasting cultures and the area of identity negotiation.

The use of a diagram such as that displayed in Figure 1 has been used by other writers as a means of illustrating social tension. Morgan (1997) used a similar diagram to advance an argument of workplace relations in a political context. Conley and Barot, (1996), in a discussion of human rights and education, used a similar diagram to emphasize that such social spaces can be sites of peaceful coexistence in spite of existing differences. Griffin (1977) used such a diagram to show how sortal relativity can illustrate shared and unique elements of identity; the tension in this instance lies within how one employs the I-predicate in a given language when making assertions regarding the self. The use of this kind of diagram can be a useful way of illustrating relationships where differences, such as differences in culture, can lead to social tension.

Because the illustration in Figure 1 is that of a Venn diagram, the interpretation of this figure may merit analysis in terms of set theory. The two sets in the illustration-Aboriginal culture and identity, and non-Aboriginal culture and identity-are intended to refer to how the respective histories, cultures, values, and experiences are manifest in individual and collective ideals and behaviours. The social space illustrated in Figure 1 can be interpreted by continuing with set theory analysis; the intersection of the two sets may be regarded as an area where elements of both sets are prevalent. By using a Venn diagram to represent an existing, dynamic social system, this intersection should be characterized as an area where culture and identities of both Aboriginal and non-Aboriginal peoples are prevalent. However, such analysis obscures the socio-cultural evolution that may be at work in this model.

This social space can also be interpreted, perhaps more correctly, as an area of overlap. In this interpretation, the area of overlap is not one where elements of one set are combined with another and reflected by showing common elements. In this interpretation, elements of one set obscure similar elements of another. In this interpretation, the overlap reflects elements of Aboriginal heritage, culture, and language that have been obscured by similar elements from the non-Aboriginal set. The phenomenon of the overlap-in the Canadian context being a EuroCanadian obfuscation of indigenous identity, was reflected by Bartko (2000), who alluded to this overlap by citing the effects of colonization on his own identity: 
The crowd of Indians ranged before the marquee had lost all semblance of wildness of the true type....It was plain that these people had achieved, without any treaty at all, a stage of civilization distinctly in advance of many or our treaty Indians to the south after twenty-five years of education. Instead of pain and feathers, the scalp-lock, the breech-clout, and the buffalo robe, there presented itself a body of respectable-looking men, well dressed and evidently quite as independent in their feelings as any like number of average pioneers in the East (p. 264).

The existence of a EuroCanadian cultural overlap that continues to obscure Aboriginal identity reflects a possible truth about the development of a national identity in Canada. The social space where perspectives between the multiple ethnic and racial groups in Canada intersect cannot adequately reflect a national concept of identity when this kind of overlap occurs; the dominant society has too profound an impact upon those in the lower echelons of Canada’s social hierarchy (Rohmann, 1999). Arguably, this is why Canada's Aboriginal peoples have adopted non-Aboriginal traditions, values, and institutional customs to such a significant extent.

One may suggest that the relationship illustrated in Figure 1 no longer adequately reflects the ethnic diversity of Canada's peoples, and that multiculturalism, the "ideal of the harmonious coexistence of differing cultural or ethnic groups in a pluralist society at its core" (Cashmore, 1996, p. 244), would require the recognition of a multiplicity of non-Aboriginal realms of culture that are not those of the colonial peoples who arrived centuries ago (i.e., those who have immigrated to Canada from countries other than those colonial powers involved in the conquest of North America). The ideal suggests that the harmonious coexistence of these differing peoples would encourage respect of the near countless differences related to culture and identity in Canada (Derricott, 1998); the binary nature of the relationship illustrated Figure 1 is view, may not be applicable. However, from the perspective of scholars with an interest in Aboriginal identity issues, employing the ideals associated with multiculturalism in the area of Aboriginal identity negotiation may be a misguided undertaking (Levin, 1993).

Interestingly, Eisenberg (2006) asserted that the purpose of multicultural citizenship was "to ensure that each individual has equal access to a secure cultural context and that possessing a minority cultural identity is viewed as conventional and fully accepted within mainstream society" (p. 6). The access espoused by this ideal has not been rendered to Aboriginal peoples, particularly primary and secondary students, in Canada; Aboriginal students continue to be denied secure cultural contexts in Canada's educational systems (Schissel \& Wotherspoon, 2003) and many Aboriginal peoples continue to lack acceptance in many aspects of mainstream society (Johnson, 2006). For many Aboriginal peoples, the binary relationship illustrated in Figure 1 is more accurate; it reflects the continued insurgency of non-Aboriginal peoples and nonAboriginal cultures on Turtle Island (Alfred, 1999) —as Ermine (2007) reminds us, the space reflected in Figure 1 is "a space between two entities...a space between the Indigenous and Western thought worlds” (p. 194). In surveying the argument favouring the ideal of multiculturalism, Varadharajan (2000) wrote that:

The unsavoury history of Canada's treatment of its Indigenous peoples and its immigration policies - as well as the unmistakable presence of those who are sometimes patronizingly referred to as "visible minorities"-have in part been responsible for 
Canada's interest in engaging cultural differences. This interest has led to the idea of a cultural mosaic as distinct from a cultural melting pot, such as is found south of the border. All parts of the mosaic, however, are not created equal. The mosaic occasionally implies satellite cultures revolving around the two founding cultures or invokes the concept of unity in diversity, neither of which negates the peripheral status of "other" cultures. Even if one envisaged the mosaic as a whole that exceeded the sum of its parts, the opposite would not be permissible: that is, the parts could not exceed the whole and are more or less contained by it. (p. 144)

The strength of a shared identity can be dependent on the role in which identity, ethnocultural identity in particular, is prevalent in an individual's self-concept. Identity may be a potentially important element of citizenship because it may be regarded as the tool with which individuals and groups define themselves, and their relationship to their community. Identity is frequently associated with ethnicity: group classifications based on common ancestral, religious, linguistic or cultural backgrounds. These notions suggest that the concept of Canadian identity has a questionable connection to any identity that is representative of Canada's diverse population; even more questionable is its connection to Canada's Aboriginal peoples. The challenge for educators across Canada is the task of facilitating identity development that is reflective of national and regional ideas, and embodies aspects of identity that are congruent with the Aboriginal experience. Therefore, the challenge for educators may involve addressing divergent cultural backgrounds in the classroom such that the area of identity negotiation, as illustrated in Figure 1, does not result in an identity overlap; such an overlap will continue to obscure traditional Aboriginal identities amongst Aboriginal students.

\section{Implications for Citizenship}

The relationship between identity and citizenship in the realm of public education can be appreciated through a survey of provincial curriculum documents in the area of social studies. In the current Grade 10 curriculum for social studies in Manitoba (Manitoba Education, Citizenship and Youth, 2006), the connection between citizenship and identity is illustrated:

Canada is a complex country that requires special qualities in its citizens. These citizenship qualities include....a sense of shared identity as Canadians, combined with a realization that Canadian identity is multi-faceted, open to debate, and not exclusive of other identities. (p. 15)

Citizenship is not simply one's affiliation with a particular nation state or political entity. Some writers have argued (Sears, 1996) that citizenship is a status that involves recognition of subjective, pre-existing, and constructed human connections to a community, nation, or other social entity. These human connections, which may be understood as relationships between personal or collective ideals and the formal and informal social structures prevalent in the greater society, necessitate the acknowledgement of identity and its influence upon those connections. Citizenship, as a scholarly concept, requires the concept of identity as one of its constituent components in order to satisfy the conditions of ethnic and cultural membership on which citizenship is supposed to be built. Canada's multicultural policies, which emphasize the celebration of the numerous racial and ethnic identities of present-day Canada, have exasperated 
cultural evolution and have done little for the struggles of self-realization that are borne by Canadian Aboriginal people; such policies should be scrutinized because they emphasize only ethnically-specific values and not the unique manifestations of identity that exist in Canada and allegedly inform the ideals associated with multiculturalism.

Identity is an essential element of the human condition (Niezen, 2003). Canada's Aboriginal population represents a collective of identities that is diverse and unique, each of which speak to a storied past of honour, wisdom, and struggle. Canadian citizenship, an idealism that is frequently purported by government as one that encompasses all of Canada's ethnic backgrounds (Department of Justice Canada, 1988; Citizenship and Immigration Canada, 2004), does not appear to be congruent with the values of equality and the stated spirit of multiculturalism. At present, Canadian citizenship serves as a mechanism for control over crucial elements of personal and collective self-concept, and does little to reflect the diversity of Canada's Aboriginal population and their struggle for recognition; this mechanism is at work in numerous social forums, including Canada's public schools (Battiste \& Semaganis, 2002). Educational systems in Canada have been charged with the task of developing good citizens (Bear-Nicholas, 1996), a task that should be approached with an understanding that Canadian citizenship has discordant links with the concept of identity.

Citizenship is a problematic issue for all citizens in Canada because of its awkward association with the concept of identity. Social studies curricula across Western Canada address skills and outcomes that can be associated with specific citizenship values. Although such curricula across Western Canada deal with citizenship as an academic subject, citizenship development is a process that can and should be employed throughout all aspects of school operations, not just in the social studies class (Levin, 1998). A possible concern regarding these processes of citizenship development is that they may leave students and teachers with only a denotative understanding of the concept of citizenship; one that is substantiated by example only and does little to provide insight into its rational and philosophical underpinnings. This way of addressing citizenship provides problems for researchers when faced with the issue of discussing Canadian Citizenship. Thus, "what is Canadian citizenship?” is a question that is addressed at the current time with the citation of intangible ideals and behavioural imperatives - the result of Canada's multicultural climate and policy regime. Identity should be inextricably connected to citizenship, and to omit the significance of Aboriginal identities from Canada's identity is to support an unjust status quo; a status quo that is reflected in Figure 1 discussed earlier.

In the realm of education, Aboriginal students are frequently exposed to subject matter that does little to facilitate the development of an identity that is informed by the traditional cultural mores of their peoples (Saunders \& Hill, 2007). The Eurocentric educational programming that is delivered to many Aboriginal students in Canada may provide skills necessary for developing active citizens, but such programming is carried out with an omission of appropriate content that is relevant to the students in question and provides opportunities to challenge Canada's cultural status-quo in a way that solidifies Aboriginal identity (Critchly et al., 2007). Through language, community relationships, and traditional knowledge, Aboriginal students may be provided the opportunity to develop an identity of their own (Neganegijig \& Breunig, 2007) — one that is informed by the experiences and legacies of their ancestors and communities. When a representative and empowering identity has been developed and celebrated 
by Aboriginal people in Canada, this identity can offset the insurgent hegemonic culture that currently exists in Canada.

This article's focus is contemporary Aboriginal identity and its implications for citizenship education in Canada. Presenting this identity as an evolving phenomenon instead of something that is static may be regarded as problematic by some-problematic because cultural and linguistic development movements amongst Canada's Aboriginal peoples may be predicated on the notion that traditional manifestations of Aboriginal identity are exactly that: traditional and should be preserved. The balance that may be important to consider may be reflected by those dimensions of Aboriginal identity that can be respective to one's ethno-cultural background, yet also reflect what is important of modern day life. Societal emphasis upon aspects of modern life as part and parcel with contemporary citizenship that have become an organic part of Canadians' lives, including Aboriginal peoples, have been facilitated in our schools—-public and First Nations.

Emberley and Newell (1994) wrote, "Education stands or falls by the principle that virtue can be taught” (p. 3). This perspective may be important for Canadian educators to consider-if one accepts that virtue is not a constant amongst ethnic groups in Canada, what characterizes virtue for Aboriginal peoples? The length, depth, and breadth of diversity reflected by the term Aboriginal may mean that this question is rather difficult to answer. Perhaps the notion that ethnic identity should be regarded as heterogeneous due to transcultural aspects of Canadian life may require an outlook on Aboriginal identity that is more contemporary and reflective of the societal changes currently seen. Is it not incumbent on us to discover what virtue is for a particular group of people? If a manifestation of virtue is to be regarded as an important aspect of a persons or peoples' self-concept, then my role as an educator may be clear, and my responsibility in the acquisition of an appropriate understanding of a people's virtue is what continues to inform this work in the continued understanding of all peoples on Turtle Island.

The implications for teachers, particularly in regard to awareness of Aboriginal issues, may be too significant to overlook. As many seek to understand how to make space for the inclusion of, and respect for, the Canadian Aboriginal experience, authorities in public education have explored ways to develop programming that is responsive to this movement in a rather brief period of time. A number of provincial departments of education now require that any graduate of a teacher education program should have completed at least one course in Aboriginal education. Many jurisdictions have attempted to increase the number of Aboriginal educators in and have created support centres for Aboriginal students. A number of Canadian universities have attempted to recruit prospective Aboriginal students and have developed professorial positions to support Aboriginal education. Some campuses have even established buildings devoted to Aboriginal students where ceremonies and gatherings can take place.

But initiatives such as these require an essential recognition: With every aspect of identity that is cited, with every building that is built, with every ceremonial activity undertaken and with every artefact that is displayed, observed and critiqued, there is a perspective-that commentary that explores the people and experience associated with a given initiative. Sometimes, this sort of exploration is not as rich as is could otherwise be: Physical education teachers sometimes introduce lacrosse in an acultural manner; history teachers sometimes 
discuss the life of Louis Riel from a colonist's perspective; and, education professionals of numerous fields frequently discuss spirituality in opposition to mainstream perspectives in a manner that trivializes ancestral beliefs. That is why the term perspective is so essential to this field: It emphasizes the focus on the unique manifestations of specific Aboriginal peoples experiences. When one overlooks the inclusion of perspective, one may run the risk of tokenism - the employment of Aboriginal education as an exercise in activity-based learning without insight into the peoples for which they are associated.

In citing the importance of Aboriginal identity as a part of perspective, one may ask if the employment of Aboriginal perspectives is an exercise in exploring just the past (i.e., is it just a historical exercise)? Manitoba Education and Youth (2003) stated these goals for Aboriginal students in regard to perspectives:

- $\quad$ to develop positive self-identity and

- $\quad$ to participate in a learning environment that will equip students with the ability to fully participate in the unique civic and cultural realities of Aboriginal communities. (p. 2)

What may be important to these goals is the recognition that such developments will occur in contemporary Canadian society where relationships and mutual influence has and continues to have an influence on Aboriginal peoples' identities. Awareness of such phenomena is essential to ethno-cultural preservation because of the attitudinal changes that will no doubt accompany such evolution. In education, the context in which perspectives are explored may be regarded as rather important, and the balance between ethnic identity and the imperatives associated with Aboriginal perspectives in education represent an area of study that must continue for the benefit of understanding virtue and its association with Aboriginal identity. 


\section{References}

Adams, H. (2000). Challenging Eurocentric history. In R. F. Laliberte, P. Settee, J. B. Waldram, R. Innes, B. Macdougall, L. McBain, \& F. L. Barron (Eds.), Expressions in Canadian Native studies (pp. 40-53). Saskatoon, SK: University Extension Press.

Alfred, T. (1999). Peace, power, righteousness: An indigenous manifesto. Don Mills, ON: Oxford University Press.

Barron, J. (2002). Romancing the "other” in Aboriginal support work. In J. Bird, L. Land, \& M. Macadam (Eds.), Nation to nation: Aboriginal sovereignty and the future of Canada (pp. 227-246). Toronto, ON: Irwin Publishing.

Bartko, P. (2000). Lesser Slave Lake Aboriginal population circa 1899— the community quandary—choosing between treaty and scrip. In D. Crerar \& J. Petryshyn (Eds.), Treaty 8 revisited: Selected papers on the 1999 centennial conference. Grande Prairie, AB: Grande Prairie Regional College.

Battiste, M. (2005, October). Research involving Indigenous peoples: Issues for researchers. Paper presented at the University of Saskatchewan, Saskatoon, SK.

Battiste, M., \& Semaganis, H. (2002). First thoughts on First Nations citizenship: Issues in education. In Y. M. Hebert (Ed.), Citizenship in transformation in Canada (pp. 93-111). Toronto, ON: University of Toronto Press.

Bear-Nicholas, A. (1996). Citizenship education and Aboriginal people: The humanitarian art of cultural genocide. Canadian and International Education, 25(2), 59-107.

Cashmore, E. (1996). Dictionary of race and ethnic relations (4th ed.). New York: Routledge.

Citizenship and Immigration Canada. (2004). A look at Canada. Ottawa, ON: Author.

Cogan, J. J. (2000). Citizenship education for the $21^{\text {st }}$ century: Setting the context. In J. J. Cogan \& R. Derricott (Eds.), Citizenship for the 21st century: An international perspective on education (pp. 1-21). London: Kogan Page.

Cohen, A. (2007). The unfinished Canadian: The people that we are. Toronto, ON: McClelland \& Stewart.

Conley, M. W. M., \& Barot, E. (1996). Human rights education: Present and future trends. Canadian and International Education, 25(2), 215-233.

Critchly, K. A., Timmons, V., Walton, F., Bryanton, J., McCarthy, M. J., \& Taylor, J. (2007). Mi'kmaq children's perceptions of education. Canadian Journal of Native Education, 30(2), 217-230. 
Dennis, R. M. (1996). Social Darwinism, scientific racism, and the metaphysics of race. Journal of Negro Education, 64(3), 243-252.

Department of Justice Canada. (1988). Canadian multiculturalism act. Retrieved from http://laws.justice.gc.ca/en/C-18.7/text.htm

Derricott, R. (1998). National case studies of citizenship education. In J. J. Cogan \& R. Derricott (Eds.), Citizenship for the $21^{\text {st }}$ century: An international perspective on education (pp. 2392). London: Kogan Page.

Eisenberg, A. (2006). Introduction: New approaches to freedom in Canada. In A. Eisenberg (Ed.), Diversity and equality: The changing framework of freedom in Canada (pp. 1-14). Vancouver, BC: UBC Press.

Emberley, P. C., \& Newell, W. R. (1994). Bankrupt education: The decline of liberal education in Canada. Toronto, ON: University of Toronto Press.

Erasmus, G., \& Sanders, J. (2002). Canadian history: An Aboriginal perspective. In J. Bird, L. Land, \& M. Macadam (Eds.), Nation to nation: Aboriginal sovereignty and the future of Canada (pp. 3-11). Toronto, ON: Irwin Publishing.

Ermine, W. (2007). The ethical space of engagement. Indigenous Law Journal, 6(1), 193-203.

Ferguson, J. (2005). Anthropology and its evil twin: "Development” in the constitution of a discipline. In M. Edelman \& A. Haugerud (Eds.), The anthropology of development and globalization: From classical political economy to contemporary neoliberalism (pp. 140153). Oxford, UK: Blackwell Publishing.

Findlay, L. M. (2000). Forward. In M. Battiste (Ed.), Reclaiming Indigenous voice and vision (pp. IV-XIII). Vancouver, BC: UBC Press.

Frideres, J. S., \& Gadacz, R. R. (2008). Aboriginal people in Canada. Toronto, ON: Pearson Education.

Friesen, J. W., \& Friesen, V. L. (2002). Aboriginal education in Canada: A plea for integration. Calgary, AB: Detselig.

Giroux, H. A. (1997). Pedagogy and the politics of hope: Theory, culture, and schooling. Boulder, CO: Westview Press.

Griffin, N. (1977). Relative identity. Oxford, UK: Oxford University Press.

Heater, D. (1999). What is citizenship? Cambridge, UK: Polity Press.

Holder, C. (2006). Culture as a basic human right. In A. Eisenberg (Ed.), Diversity and equality: The changing framework of freedom in Canada (pp. 78-96). Vancouver, BC: UBC Press. 
Ignatieff, M. (2000). The rights revolution. Toronto, ON: House of Anansi Press.

Johnson, W. (2006). The challenge of diversity. Montreal, PQ: Black Rose Books.

Lawrence, B. (2004). “Real” Indians and others: Mixed-blood urban Native peoples and Indigenous nationhood. Vancouver, BC: UBC Press.

Levin, B. (1998). The educational requirement of democracy. Curriculum Inquiry, 28(1), 57-79.

Levin, M. D. (1993). Introduction. In M. D. Levine (Ed.), Ethnicity and Aboriginality: Case studies in ethnonationalism (pp. 3-8). Toronto, ON: University of Toronto Press.

Li, Z. (2002). The administrative practices of principals toward the goal of preparing students for citizenship in Manitoba's high schools. Unpublished doctoral dissertation, University of Manitoba, Winnipeg.

Little Bear, L. (2000). Jagged worldviews colliding. In M. Battiste (Ed.), Reclaiming Indigenous voice and vision (pp. 77-85). Vancouver, BC: UBC Press.

Manitoba Education and Youth. (2003). Integrating Aboriginal perspectives into curricula. Winnipeg, MB: Author.

Manitoba Education, Citizenship and Youth. (2006). Senior 2 social studies: Geographic issues of the $21^{\text {st }}$ century. Winnipeg, MB: Author.

Manville, P. B. (1990). The origins of citizenship in ancient Athens. Princeton, NJ: Princeton University Press.

Morgan, G. (1997). Images of organization (2nd ed.). Thousand Oaks, CA: SAGE Publications.

Neganegijig, T., \& Breunig, M. (2007). Native language education: An inquiry into what is and what could be. Canadian Journal of Native Education, 30(2), 305-321.

Niezen, R. (2003). The origins of Indigenism: Human rights and the politics of identity. Berkeley, CA: University of California Press.

Ortner, S. B. (2006). Anthropology and social theory: Culture, power, and the acting subject. Durham, NC: Duke University Press.

Perry, J. (2002). Identity, personal identity, and the self. Indianapolis, IN: Hackett Publishing.

Ray, A. J. (2005). Introduction. In A. J. Ray (Ed.), I have lived here since the world began: An illustrated history of Canada's Native people (pp. xii-xvii). Toronto, ON: Key Porter Books.

Rohmann, C. (1999). A world of ideas: A dictionary of important theories, concepts, beliefs, and thinkers. New York: Ballantine Books. 
Saunders, S. R., \& Hill, S. (2007). Native education and in-classroom coalition-building: Factors and models in delivering an equitous authentic education. Canadian Journal of Education, 30(2), 1015-1045.

Schissel, B., \& Wotherspoon, T. (2003). The legacy of school for Aboriginal people: Education, oppression, and emancipation. Don Mills, ON: Oxford University Press.

Sears, A. (1996). “Something different to everyone”: Conceptions of citizenship and citizenship education. Canadian and International Education, 25(2), 1-16.

Trigger, B. (1998). Sociocultural evolution: Calculation and contingency. Oxford, UK: Blackwell Publishing.

Turner, D. (2006). This is not a peace pipe: Towards a critical Indigenous philosophy. Toronto, ON: University of Toronto Press.

United Nations Development Programme. (2007). Human development report 2007/2008. New York: Author.

Varadharajan, A. (2000). The "repressive tolerance” of cultural peripheries. In M. Battiste (Ed.), Reclaiming Indigenous voice and vision (pp. 142-149). Vancouver, BC: UBC Press.

Waldram, J. B. (1997). The way of the pipe: Aboriginal spirituality and symbolic healing in Canadian prisons. Peterborough, ON: Broadview Press. 